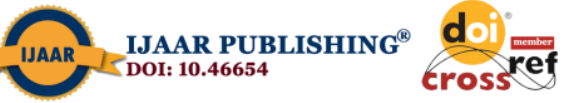

International Journal of Advanced Academic Research | Social and Management Sciences | ISSN: 2488-9849 Vol. 6, Issue 6 (June, 2020) | www.ijaar.org

Journal DOI: 10.46654/ij.24889849 | Article DOI: 10.46654/ij.24889849.s662

\title{
UNENDING WAR ON BOKO HARAM TERROR IN NORTHEAST NIGERIA AND THE NEED FOR DEPLOYMENT OF MILITARY ROBOTS OR AUTONOMOUS WEAPONS SYSTEMS TO COMPLEMENT MILITARY OPERATIONS
}

\author{
Dr. Temitope Francis Abiodun \\ Institute for Peace and Strategic Studies \\ Faculty of Multidisciplinary Studies \\ University of Ibadan, Nigeria \\ E-mail: abiodun.temitope3@gmail.com \\ Captain Raheem Taofeek \\ Navigation and Direction, Nigerian Navy (NN 1940) \& \\ M.Sc Strategic Studies Student, \\ Institute for Peace and Strategic Studies \\ Faculty of Multidisciplinary Studies \\ University of Ibadan, Nigeria
}

\begin{abstract}
The current global technological advancements have opened ways or made it possible for military robots to become effective weapon systems in numerous military operations. Military experts hold that autonomous weapons systems not only confer significant strategic and tactical advantages in the battleground but also that they are preferable on moral grounds to the use of human combatants. These military robots are observed to be highly helpful in all sorts of military and non-military operations. The increasing spate of terrorist attacks and killings that have led to a large numbers of casualties both on the military side and that of civilians in northeast Nigeria may have necessitated the deployment of robots to complement military operations respectively. The study relies on both primary and secondary sources of data. The study employs the use of frustration-aggression theory to describe the bane behind protracted reign of terror in the zone. The study also aims to show the level of brutal killings and numerous losses suffered in the region by men of the Nigerian armed forces in the hands of Boko Haram terrorists. The research work also examines the need for deployment of robots to complement efforts of the military troops in their operations in the region. In its findings, the study is able to discover that Nigeria Military has suffered several losses in its war against Boko Haram terror, losing a large numbers of its men; while the reign of terror persists and seems unending so soon. Recommendations are offered by the study to ensure swift deployment of military robots to complement military operations in: military transportation; aerial surveillance; manning ground-level attacks; landmine detection; searching of dangerous terrains or locations and rescue missions; and attacking and firing activities. Lastly, the study assists by illustrating how the deployment of robots in military operations in the northeast Nigeria would help put an end to reign of terror out rightly.
\end{abstract}

Keywords: Military operations, Robot, Weapon systems, Boko Haram Terror, Unmanned Aerial Vehicles, Northeast Nigeria. 


\section{INTRODUCTION}

Globally and at present, the nature and dimensions of warfare have changed drastically as technology now plays a major role in directing and shaping warfare tactics. The various threats being faced by militaries are probable, with populated places as battlefields, and enemies are therefore, currently tactically innovative, highly networked and intelligent. The scenario suppresses the superiority the armed forces may possess in terms of conventional warfare capabilities. However, technological advancement has enabled states the capability to counter enemy attacks in an efficient and effective manner (James, 2007). An instance of such advancement has been in the area of military robotics as robots in the military, today, are an alternative to human soldiers in all ramifications. The military robots are designed to execute a range of combat tasks, from picking off snipers to carrying out target acquisition with greater accuracy, compared to human soldiers. The robots can now be deployed in situations and areas that are dangerous and can maim troops. Military robots usually provide a great back-up whenever there is heavy artillery fire and also reduce the number of human casualties. They can also map a potentially large hostile area by accurately detecting a variety of threats (Jeffrey, 2012).

Current studies depict it to be realistic that autonomous systems would very soon be the most widely utilized tools of warfare globally. Such autonomous complexes adorned and equipped with artificial intelligence and weapon systems, may be very different from the fictional humanoid machines with weaponry designed to be highly effective, well-construed and directed by humans simultaneously. These may take various sizes and forms - they can be wheeled, winged, or tracked, swimming, rolling or flying equipment, of any form and practically of any function (Michael, 2014). In short, artificial intelligence is gaining momentum from medicine to production, from farming to physical exercise, from birth control to mass destruction in human fantasy as well as in the everyday realities of postmodern urban life. It can save and nurture life or destroy the living (Amitai and Oren, 2017). Robots or autonomous weapons system utilization in the military has gained affirmation in all ramifications. Military robots are found in peace keeping operations as well as in combat actions, in urban warfare as well as in the digital battlefield. They comprise an integrated part of the armoury of the modern national and allied forces and provide for much of their capabilities helping to gain the upper edge at all battles. Robots are optimized to their tasks all way down to the choice of (in most cases either silicon-based or natural) materials. The existence of such technologies raises not only engineering questions but also those of jurisdiction and utilization. Military experts hold that autonomous weapons systems not only confer significant strategic and tactical advantages in the battleground but also that they are preferable on moral grounds to the use of human combatants. These military robots are observed to be highly helpful in all sorts of military and non-military operations (Amitai and Oren, 2017). 


\section{CONCEPTUAL CLARIFICATIONS}

\section{Boko Haram Terror}

Few years after the return of civilian rule in Nigeria, there existed one Mohammed Yusuf who happens to be a very young charismatic cleric, looking for his own perception of Islam, put in place a movement known as Yusufiya (meaning followers of Yusuf) in Maiduguri, Borno State, northeast Nigeria. Rejection of formal education actually gained a central ideology of the Movement. The group was named the "Nigerian Taliban" by local people in the north-east region of Nigeria and eventually became popularly called "Boko Haram" which in Hausa language, means "Western education is forbidden" (Abiodun, Opatoki, Adeyemo and Obi, 2010). The terrorist sect with a reference to Yusuf's widely spread sermons, and condemned all aspects of Western education to be claiming that it contradicted Islamic principles and beliefs. The sermons lured many people in that part of the country, including students, school drop-outs, unemployed youth, who saw a radical form of Islam as the antidote to the alienating social inequalities and economic impoverishment that overtook their lives. In the same vein, Yusuf's followers included high-ranking elites in their midst such as: politicians, government officials, and wealthy businessmen (Abiodun et al., 2020). The group's member population swelled with young men from across northern Nigeria, attracted by Yusuf's fiery sermon against unjust and corrupt secular governments. Mohammed Yusuf was later captured by the Nigeria Army on July 30, 2009 after years of violence in Maiduguri, and the Nigeria police executed him days later having been handcuffed at police headquarters in Maiduguri. This act thereafter, made the group to be more radical (Abiodun, 2016).

In the year 2010, one of Yusuf's deputies, Abubakar Shekau, however assumed the mantle of leadership and renamed the sect to be "Jama'atu Ahlis Sunna Lidda'awati wal-Jihad," an Arabic phrase with the meaning "People Committed to the Propagation of the Prophet's Teachings and Jihad." Under his leadership, Boko Haram became intensely violent with devastating consequences for school-age children (Abiodun et al., 2020). However in 2015, Shekau pledged Boko Haram's allegiance to the Middle-East-based terror group known to be Islamic State of Iraq and Syria (ISIS) and despite the unholy alliance, Boko Haram has increasingly continued to operate independently. And the group was ranked the world's deadliest terrorist group in the year 2014 (Institute for Economics \& Peace, 2015).

\section{Military Robots}

Military robots come in different shapes and sizes depending on the requirement, and they may be remotely controlled or fully autonomous. Robots consist of different types of payloads depending on the application. Depending on the application requirements, sensors, detectors, weapons, programmed software, and other payloads can be equipped on robots used in the military (Gary, 2017). Militaries are focusing increasingly on the development of various new robot technologies that can be helpful for armies in case of war. For example, the Defense Advanced Research Projects Agency (DARPA) finances a robotic submarine system 
that could be used intelligently for several applications ranging from detecting underwater mines, engaging in anti-submarine operations, and protecting ships in harbours. All these merits enable the militaries globally to use robots for a range of military operations. An analysis in weapons market indicates that the military robots industry is expected to reach USD 30.83 billion by 2022, at a CAGR of 12.92\% from 2017 to 2022 (Gary, 2017).

The development of technologies, the application of research results, the appearance of new, and more complex machines are now becoming more dynamic and changes the face of wars too. Military robot with the application of independent tools for military operations is not any more only a great vision but everyday reality. Drones or Unmanned Aerial Vehicles (UAVs) comprise the military equipment of the most versatile employed currently in the arsenal of modern warfare (Szegedi and Belesi, 2015). It is becoming more and more believable an idea that in the very close future battles, even wars can be fought by robots and mercenaries between not only nation states or their alliances but also between irregular militia groups, terror organizations, international criminals or more traditional political or economic units of all types and levels. The growth of operational speed means that the attacked have less and less time to respond in kind. Defence therefore is more and more forced to apply preventive action to avoid destruction (Ibid).

\section{Types of Military Robots}

There have been several major strides in the development of military robotics due to the technological advancements in automation and sensors systems. Today, robots are equipped with advanced technologies of automated weapon systems having the capability to counter any attack. Responses from the study indicate that the military robots are assembled with several codes and algorithms and some of the military robotics includes:

\section{$\underline{\text { PD-100 Black Hornet }}$}

A PD-100 Personal Reconnaissance System, that can be smaller than the flat of the hand, is ready for action within a minute and, in fact, the whole equipment consisting of a flying unit and a terminal fits into a pocket-size holder. It can be mistaken for a toy but it is much more than that ... due to the micro cameras installed, the 18 gr flying unit is a well-equipped spying tool that can provide crucial visual information about whatever happens around a corner or behind a wall. It is quiet, difficult to spot, and relatively fast. The operator can be about $1 \mathrm{~km}$ away from the place of action. Its board computer is capable of both directed and independent flight. Various versions of the Hornet are in use in reconnaissance as well as any other type of intelligence operations. It can be used for search, salvage, monitoring, scouting etc. in the open as well as in closed space (Research Report, 2020).

\section{BigDog}

The quadruped robot called "Big Dog" looks like a mule and it is approximately 0.91 meters long, 0.76 meters tall and weighs $110 \mathrm{~kg}$ (Research Report, 2020). It is developed to provide 
logistical units where the conventional transport vehicles are not able to operate. The hydraulically operated legs are articulated as other animal's legs that contain damping elements which absorb the energy of the blows from steps and it recycles them in the next step. The maximum speed is $6.4 \mathrm{~km} / \mathrm{h}$ and it is able to overcome on a 35-degree slope. The robot is able to go through snow, water, and rocky terrain. Even in rocky terrain it is able to climb muddy natural paths and deliver a maximum $150 \mathrm{~kg}$ of additional weight. The onboard computer is able to follow the commands of its operator from a distance, and control the Big Dog's movement. The robot's resource is a two-stroke single-cylinder water-cooled engine. You can find the following sensors which provide the on-board movements: GPS, gyroscope, camera (stereo vision system), LIDAR (follower DPR), engine temperature, speed, hydraulic pressure, temperature, position, dynamometer, battery charge measuring sensors (Research Report, 2020).

\section{$\underline{\text { Daksh }}$}

The Daksh is an electric powered remote controlled vehicle. Its primary function is to secure, localize dangerous objects such car bombs, suspicious packages, and make easier the handling and destruction of these dangerous objects. This is not the only type of device that is designed for these tasks. The device is remotely-controlled from 500 meters distance, its arm is able to extend and remove the IEDs and the robot runs on thick rubber wheels which resist the air pressure of the explosive charge (Solon, 2016). It is able to climb stairs, blast closed doors, get over steep hills, maneuver in tight spaces, and tow suspicious vehicles from busy locations. The vehicle also contains water cannon and it is able to safely destroy anything found. The robot is equipped with a camera, IED control equipment, NBC reconnaissance system, and large-caliber shotgun. From the managing station (MCS Master Control Station) one operator control the Daksh with a remote control. It as well has a separated cabin which has the correct equipment to transport the disarmed bombs (Research Report, 2020).

\section{Goalkeeper}

Goalkeeper was designed in the year 1979 in the US. Goalkeeper is a completely automated weapon system that is usually deployed to protect warships against missiles, aircraft and surface swimming vehicles or against any threat of water above the surface. The autonomous weapon system is able to execute detection and monitoring as well as destruction of enemies' terrains and objects. It also possesses a dual locator system that identifies and prioritizes locations and attacks the highest priority threats simultaneously. Goalkeeper is equipped with a GAU-8/A Avenger $30 \mathrm{~mm}$ Gatling gun used also on the A-10 Thunderbold II aircraft. The high precision seven-barrel cannon offers full round defence and is capable of executing 4200 shots per minute (Northrop, 2016).

The application of robotics may easily lead to the creation of a well-greased mechanistic system aimed at the total destruction of targets. They are remotely controlled and monitored. In the same vein, several factors have aided the manufacturing and usage of the military robots as revealed by the (Research Report, 2020) to include: 
(i) Technology, which has resulted to mass production and miniaturization which is now becoming cost-effective.

(ii) A number of cultural developments: education and internet, providing all social layers with knowledge and information, ideas and ideals and also strengthening the belief that (biological, i.e. human and non-human) life is valuable.

(iii) Becoming a core value of democracies whereby the society is expected to provide the necessary environment and inputs for the individual to live a meaningful life.

(iv) Machines, robots are at least ethically valued to be worth less than human life.

(v) Machines, due to the rapidly developing IT technology, are faster in sensing, measuring and analyzing (in pre-programmed ways) much larger sets of data than those any human being may process, therefore their reaction may follow faster.

(vi) Machines remain in function under extreme weather conditions or other environmental pressures where human beings could not.

(vii) Machines, unlike people, do not get fatigued or tired as they can handle all monotonous processes quite well.

These military robots are usually programmed and prepared for their tasks; the preparation requires the professional collaboration of engineers and other specialists. The ongoing IT revolution and the emerging new technologies make it possible that unmanned vehicles to be globally used. The development of artificial intelligence that has made the evolution of automated machines into autonomous ones has now become a trend in military complexes in all ramifications (Northrop, 2016).

\section{THEORETICAL FRAMEWORK}

Researchers have made frantic efforts trying to find out what could have prompted the Boko Haram terror in northeast Nigeria. A large number of researchers discussed much on religion to have been the main motive of the act of violence perpetrated by Boko Haram killers (Abiodun, Opatoki, Adeyemo, and Obi, 2020). It is argued that there is something in the terrorists' religion that makes them to unleash mayhem or violence in the region. Though the submission may sound a bit deficient, as there is no significant relationship between being an adherent of Islam and being a terrorist. As a result of this, the study employs the use of frustration-aggression theory, a social and psychological theory that has gained more in several fields of study, explaining aggressive human behaviour of people in the society. However, there is a mutual relationship between frustration and aggression (Miller, 1941). The belief of nexus between frustration and aggression was first made by: John Dollard, Leonard W. Doob, Neal E. Miller, Orval H. Mowrer and, Robert R Sears in their co-authored work "Frustration and Aggression (1939)" while the theory got revised by Neal E. Miller (1941) and Leonard Berkowitz (1969) respectively. Frustration according to the scholars means "an interface with the occurrence of an instigated goal-response at its proper time in the behaviour sequence" (Dollard et al., 1939). 
Moreover, it also denotes a situation when an issue in which the realization of a desired aim of a man or group of persons gets hindered or unattained. Summarily, aggression is a sequence of behaviour, the goal-response to which is the injury of the person toward whom it is directed. Abiodun, Opatoki, Adeyemo, and Obi (2020) argue that the upsurge of aggressive behaviours usually presupposes the existence of frustration and, also the existence of frustration always brings up some form of aggression. Miller (1941) two years later reformulated the original assumption that frustration produces instigations to a number of various forms of response, one of which is an instigation to some form of aggression. Concerning the Boko Haram terror, the theory of frustration-aggression enables adequate comprehension of terrorist activities in the northeastern part of Nigeria. It is believed that it is as a result of the frustration or inability to achieve their (Boko Haram fighters) personal goals which may have involved: ending Western education in the country, forcefully foisting their Islamic religion on the people, unemployment and impoverishment of the locals. Failure to achieve these, they become frustrated and therefore appear highly aggressive, terrorizing Nigerians (Abiodun et al., 2020).

\section{METHODOLOGY}

The research work relies on both the primary and secondary sources to get its data. The sources are quantitative and qualitative means. Copies of questionnaire was administered online while interview was conducted via Zoom platform with some experts on robot and drones usage in the Nigerian Armed Forces comprising; Air Force, Army, Navy, Nigeria Institute for Policy and Strategic Studies, NIPSS, Kuru, Jos, and also some experts in the field of Mechatronic Engineering, Federal University of Technology, Akure, Nigeria, the Department of Mechanical Engineering, Yaba College of Technology, Yaba, Lagos, Nigeria, and the Department of Mechanical Engineering, Federal University, Oye-Ekiti, Nigeria respectively. The secondary data were sourced from existing literature on the topic such as: books, internet, journals, newspapers, magazines, research/conference papers, and other related documents respectively. The study analysis is content-analyzed.

\section{BRIEF OVERVIEW OF RECENT LOSSES SUFFERED BY NIGERIAN SOLDIERS UNDER THE BOKO HARAM TERROR IN NIGERIA}

Boko Haram has killed tens of thousands of Nigerian military forces in its 10-year armed uprising in northern Nigeria. It is confirmed that Boko Haram fighters killed several Nigerian armed troops in an ambush laid near Goneri village in northern Yobe State in the first quarter of 2020. The Nigerian military suffered numerous casualties in the unfortunate attack. Though the exact number of casualties was not disclosed but few respondents put the numbers at between fifty (50) and seventy-five (75). It was indicated that the ambush took place near the town of Goneri in eastern Borno State on 20 March, 2020. Though immediately after the attack the Air Force was summoned and it raided the territory of the fighters and succeeded in killing all of them after bombarding the terrorists' hideouts (Research Report, 2020). 
In another deadly attack on the armed forces installations in the region on 18 and 19 March, 2020, the troops were able to fight back and escape from the ambush. Also at a place named "the Gorge", the soldiers were attacked from the rear when they were trying to advance. Boko Haram fighters on that day inflicted heavy casualties by opening fire on the military vehicles with rocket-propelled grenades and assault weapons. Those who were able to survive among the military troops were accepted for treatment at hospitals in Damaturu and Maiduguri respectively. A respondent (a senior Army Officer) also confirmed the attack, saying he even lost a friend and tagged the attack a huge setback for the Nigerian army. Boko Haram has killed tens of thousands in its 10-year armed uprising in northern Nigeria (Research Report, 2020). In addition, between 20th and 21st March, 2020, the fierce-looking Boko Haram terrorists killed ninety-two (92) Chadian and seventy (70) Nigerian soldiers in two separate terror attacks. A large number of respondents confirmed that about ninety-two soldiers were killed and forty-seven others got seriously injured when the insurgents attacked an army unit in Boma, a peninsula of Lake Chad that borders Nigeria. In the same vein, President Idriss Deby of the Republic of Chad visited the scene of the ambush and attack to confirm the death toll (Research Report, 2020).

Across the border, in northeastern Nigeria, dozens of soldiers died in similar ambush by Boko Haram terrorists (Enenche, 2020). The Nigerian military also suffered heavy casualties in the unfortunate attack. The militants struck several military vehicles carrying explosives and ammunition, which caused a huge fire that in turn led to a high death toll, the spokesman added. Boko Haram poses a steady threat to communities in the north-east of Nigeria and has also launched offensives in neighboring Chad, Niger and Cameroon. Since 2009, tens of thousands of people have been killed by the terrorists in the region and an estimated 2.5 million people fled their homes (Research Report, 2020).

\section{THE NEED FOR USAGE AND DEPLOYMENT OF ROBOTS IN MILITARY ACTIONS IN NORTHEAST NIGERIA}

Robot army saves and preserves the lives of soldiers who may be killed by replacing the serving soldiers in combat. Robot soldier does not get fatigued, does not sleep or hide away from the weather elements. Moreover, military robots do not while away the time by aimless chatting with friends. The best of it all is that battle robots have no passion or emotion. This assists greatly by minimizing the incidences of unethical behaviours of soldiers during combats. Therefore, the fatigue, strains, sentiments, and emotions attached to the integrity of the soldier's decisions are significantly minimized. Nigeria Armed Forces can make use of these military robots to improve continuously and get better day after day. And today, we have different types of military robots with different uses (Research Report, 2020).

\section{Military Transportation Robots}

These robotic soldiers perform transportation roles. They can replace the soldiers in the transportation of bombs, artillery, military supplies, and other materials. Although these military robots commonly have wheels, some of them come with legs instead of performing on rough terrains. Military robots used for transportation boost logistics efficiency and 
equally assist soldiers in their movements. They help soldiers to carry materials to the battlefield. Also, they equally help to pick up causalities from the battlefield. The soldiers who undertake risky combats receive payments for their task. However, they are still human and deserve to live, and so the use of robotics army in different tasks can be life-saving. Some of the life threats will be avoidable through using robotics army. At the same time, they can help in improving the transport system. For instance, robots would be handy for extracting casualties from the battlefield. They could equally improve the transportation system like the Autonomous Platform Demonstrator or APD. APD is a military transportation robot that is used by the United States (Research Report, 2020).

\section{$\underline{\text { Search and Rescue Mission Robots }}$}

The use of these types of military robots is for search and rescue missions. A robot army can be of big help in search and rescue mission inside water and wilderness. They equally come handy when there are floods, wildfires, and wreckages during an earthquake. Robot soldiers can also help in rescue missions during some incidents like tsunamis, tremors, and artificial disasters like the Chernobyl or 9/11 incident.

\section{Fire Fighting Military Robots}

This type of robot soldiers can be of great use when there is fire. It can help to save the human soldier from life threatening situations. The firefighting military robots are the type of robots that can be linked up with a hydrant to help in extinguishing the fire. They can save the lives of victims and also the lives of firefighters. These types of robotics army that assist firefighters are not yet common. However, some robot army at present is for such purposes. Some of these types of robot soldier help to investigate the situation in a fire site. There are equally some gigantic remote-controlled fire extinguishers.

\section{Armed Military Robots}

These are types of military robots that have weapons to shoot at the enemies during combat operations or in the battle fronts.

\section{Unmanned Aerial Vehicle (UAV) Robot}

These battle robots are flying robots designed for reconnaissance missions. Also, their use is for surveillance missions. Future robots may include unmanned fighters and bombers.

\section{Unmanned Ground Vehicle (UGV) Robot}

The majority of the military robot types that we have discussed are UGVs. These robots are robots that operate on the ground (Research Report, 2020).

\section{Unmanned Underwater Vehicle (UUV) Robot}

These robotic soldiers can move underwater. The uses of some types of army robots can be for surveillance purposes and equally for search and rescue missions. Similarly, the classification of the last types of military robots is according to the environment where they 
operate. They can work as military robots for rescue, surveillance, and mine clearance (Research Report, 2020).

Military Robots Can Be Protectors Too. There you have it! The fantastic roles that military robots are playing in the army and how robotic soldiers can be integrated into defense and security system to boost protection, enhance the protection of lives, and improve efficiency while minimizing costs (Research Report, 2020).

Robots, especially military robots, can be designed to carry out unsafe, murky, or recurring tasks with constant precision and regular accuracy. Therefore, it is not hard to see why more and more industries are beginning to adopt robots for different applications. This is due to their usefulness. There are different types of robots. They vary in their uses, applications, and features (Research Report, 2020). These come in diverse models or types and have different features such as the distance it can cover, the amount of payload it can accommodate, and how many axes their jointed arm contains. These are the main differences in the features of robots. Military robots can work round the clock. They do not get tired or go for breaks like human workers. Also, because robots are lifeless technologies, they can easily perform hazardous tasks that are otherwise challenging and unsafe for humans. The use of robotic technology equally boosts productivity and enhances profitability. At the same time, it can eliminate labor-intensive tasks that could pose some threats to the physical well-being of humans and result in accidents or injury (Research Report, 2020).

\section{MAJOR APPLICATIONS OR STRATEGIC OPERATIONS IN WHICH MILITARY ROBOTS ARE DEPLOYED}

\section{i. Intelligence, Surveillance and Reconnaissance (ISR) Operations}

Intelligence, Surveillance and Reconnaissance (ISR) is one of the major applications where military satellites are used. UAVs, UGVs, USVs, ROVs, AUVs, and others are extensively used in the ISR application. Small UAVs are used in the military sector mainly to provide battlefield intelligence. Currently, armed forces worldwide no longer rely on human scouts and instead use small robots, which can remain almost invisible to the enemy. These robots help monitor enemy forces or specific areas and send videos and images to the ground station with the assistance of GPS. UAVs are used for ISR operations to record potential target information that is difficult to detect. For example, WASP, a lightweight, robust, low altitude remote-controlled Unmanned Aerial System (UAS), designed and manufactured jointly by AeroVironment (US) and the Defence Advanced Research Projects Agency (DARPA), is used by the US for surveillance and reconnaissance (Merrill, 2016).

\section{ii. $\quad$ During Search and Rescue Missions}

Search and rescue is another application where robots used in the military can play a crucial role in saving lives. The majority of casualties happen due to the delay in providing necessary aid to victims. Many countries are investing heavily in minimizing the response time to save the maximum number of lives. Search and rescue robots are highly advantageous in war. 
They can manage to search, track, and rescue even in nuclear, biological, radiological, and chemical environments. They can be operated remotely by soldiers from a command center. In some cases, they can even work autonomously. Vecna Technologies is developing Battlefield Extraction-assist Robot (BEAR), which can rescue soldiers from the battlefield with no risk to human life (Friedman, 2010).

\section{iii. Combat Support for the Military Troops}

Robots in the military are deployed in combat support application for anti-submarine operations, laying mines, fire support, electronic warfare, battle damage management, strike missions, aerial refueling, etc. They also play a vital role in critical missions due to their enhanced capabilities and a certain degree of autonomy. The ability to achieve information superiority, minimize collateral damage, and fight effectively in urban areas against widely dispersed forces are the advantages offered by robots. Technological developments in army robots have led to equipping them with weapons to offer lethal capabilities in combat missions, along with the ability to make decisions without human intervention (Research Report, 2020).

\section{iv. Effective Mine Clearance at Battlefield for the Military Troops}

Mine clearance is another application where army robots can be deployed for mine reconnaissance and area clearance operations to detect and remove landmines and sea mines. A robot minimizes the risk of unexploded ordnance and other dangerous objects. Land robots and ROVs are used for mine clearance operations. For instance, in 2016, Russian military used a hi-tech "robot solider" known as Uran-6 robots to clear the historic World Heritage site of Palmyra of explosives after the area was liberated from Islamic State rule. Uran-6 robots defused almost 3,000 explosive devices including mines (Constantine and Stuart, 2016).

\section{v. Identifying and Diffusion of Explosive Ordnance Disposal}

Explosive Ordnance Disposal (EOD) robots are used to identify and disarm traps, fireworks, improvised explosive devices, and other dangerous objects in built-up areas, buildings, and vehicles. They are integrated into bomb detection systems. They can carry a variety of payloads depending on the EOD mission. Some examples of EOD robots are iRobot 510 PackBo, TALON, Remotec Andros, tEODor, and Dragon Runner which have tremendous potential in the future (Research Report, 2020).

\section{vi. Detecting and Suspending Fire Incidents}

Fire fighting robots are increasingly being used to address fire situations to avoid casualties. These robots were first employed by the US Navy and were named as Shipboard Autonomous Firefighting Robot (SAFFiR). Fire fighting robots can detect fire, implement a broad range of fire suppressing techniques, withstand high temperatures for longer periods, and respond to different types of movements. These robots can detect fire, as they are equipped with a suite of cameras, a gas sensor, and a stereo infrared camera, which help these 
robots find their way through smoke and bring the fire under control (Research Report, 2020).

vii. For Firing or Launching of Missiles: It launches and fires missiles. Drones are frequently used in these areas (Research Report, 2020).

\section{POTENTIAL THREATS ON THE USAGE AND DEPLOYMENT OF MILITARY ROBOTS}

Some of the potential threats that may bedevil the deployment of robotics in military operations are as follows:

In July 2015, an open letter calling for a ban on autonomous weapons was released at an international joint conference on artificial intelligence. It was released that the deployment of such systems is illegal. Autonomous weapons systems have been described as the third revolution in warfare, after gunpowder and nuclear arms. The use of such weapons is offensive or defensive. Thus, many assume that an effective missile defense shield is strictly defensive, but it can be extremely destabilizing if it allows one nation to launch a nuclear strike against another without fear of retaliation (Amitai and Oren, 2017).

However in April 2013, the United Nations, UN Special Rapporteur on Extrajudicial or Arbitrary Executions presented a report to the United Nations Human Rights Council. The report recommended that member states should ensure they declare and implement moratoria on the testing, production, transfer, and deployment of lethal autonomous robotics (LARs) until an internationally agreed upon framework for LARs has been established.

Also, a group of engineers, Artificial Intelligence and Robotics experts, and other scientists and researchers across the globe issued the "Scientists' Call to Ban Autonomous Lethal Robots." The statement notes the lack of scientific evidence that robots may not possess the functionality required for accurate target identification, situational awareness, and decisions on the proportional use of force. Therefore, this may cause a high level of collateral damage (Merril, 2016).

In the same vein, it is argued that it may be difficult for the military robots or autonomous weapons systems to be capable of choosing their own targets. Pursuant to this, a highly renowned Computer Scientist, Noel Sharkey, called for a ban on "lethal autonomous targeting" as it violates the "Principle of Distinction", and it is considered one of the most important rules of armed conflict because autonomous weapons systems may definitely find it very difficult to determine who is a civilian or non-combatant, at the battle field. More casualties may be recorded (Amitai and Oren, 2017).

Another major concern is the problem of accountability when autonomous weapons systems are deployed. This is evident in the submission of Ethicist Robert Sparrow when he argues that this could be ethical issue by noting that a fundamental condition of international 
humanitarian law, or jus in bello, requires that some person must be held responsible for civilian deaths. Any weapon or other means of war that makes it impossible to identify responsibility for the casualties it causes does not meet the requirements of jus in bello, and, therefore, should not be employed in war (Nicol, 2016).

Also there is an argument on the irreplaceability of human conscience and moral judgment that has to be adequately revisited. In addition, it suggests that as humans become more accustomed to machines performing functions concerning life-or-death implications, humans will most likely become more comfortable with Artificial Intelligence (AI) technology's incorporation into weaponry. And as this takes place, there is need for guiding and constraining research and development — and eventual deployment — of autonomous weapons systems (Amitai and Oren, 2017).

\section{RECOMMENDATIONS}

Myriads of studies have been conducted on Boko Haram terror and attacks in northeast Nigeria. The fact is that there is need for the deployment of military robots to assist or complement the efforts of Nigerian Armed Forces at the battlefield in northeastern region of the country. Pursuant to the above, the study arrived at the following recommendations:

i. As technologies are currently advancing globally, military robots should be made to take over those strategic or military missions as they are easily and directly operated by human-powered tools, and would definitely help in all those tasks which have pose dangerous risks to military or human lives.

ii. Robots which are operated by direct human supervision and control; submarine gadgets, reconnaissance helicopters operated from boat deck, and active aircrafts which work in high attitude would go a long way in boosting military operations.

iii. The robots would definitely be able to stabilize the military balance, give forewarning on threats and encourage fast military actions through surveillance, mapping system and intelligence gathering abilities in all sense.

iv. Military robots would be useful in analyzing the situation of things in the battle zones as the remote-controlled drones assist in the military defense purposes.

v. Military robots would transform how the military and public safety industry would conduct their analysis and engage in surveillance activities. The use of automated machines would assist to carry heavy weapons which may make you nervous. 
vi. However, these robots can potentially minimize the loss of life. Also, they can make it easier for soldiers to securely spy locations or breach enemy targets. The structures of a lot of military robots are for supporting life instead of eliminating life.

vii. Against this background, the military planning future operations and executing them need to count own dimensions of the battlefield (real or virtual space, missile defence system, and defence capability, amongst others). However, the main factor is, there is need for strategic education and training, which should be made to become an integral part of military service in all ramifications.

\section{CONCLUSION}

The developments of the past few years have changed the modus operandi of the use of the armed forces. These robotic systems would therefore need to continue to be deployed in military operations in northeast Nigeria for effective outcomes. What is more important is that the combat role of robotic powers would easily make the decisions over life and death of the Boko Haram terrorists by the press of just a button, or substituting the trained soldiers whose health would never be at risk and families not have to worry again. Benefits of military robots find their ways into strategic industries as: they would produce an accurate and more precise result. Military robots or autonomous weapons systems remain flexible and can easily perform multiple roles of annihilating all the dangerous terrorists' camps and hideouts in Yobe, Borno and Adamawa respectively. As military robotics are comparatively cheaper compared to hiring human labour (armed forces) to confront the hardened terrorists in the region; they are noiseless or unnoticeable; and these would definitely boost the military operations speedily. Military robots would help to carry out an investigation, gather intelligence, surveillance, provide support in the war front, and perform patrol tasks for the troops. However, these robots can potentially minimize the loss of life being recorded on daily basis on the part of the Nigerian Armed Forces respectively. Lastly, autonomous weapons system or military robotics would definitely make it easier for soldiers to securely spy locations or breach enemy targets. It is therefore, recommended that military robots or autonomous weapons systems be deployed to complement the Nigerian military operations in the face of an unending Boko Haram terror in the Northeastern Nigeria. 


\section{REFERENCES}

Abiodun, T.F., Opatoki, O.O, Adeyemo, D. and Obi C. (2020) Assessment of Boko Haram Insurgency Threats to Educational Development in the Northeast Nigeria: The Way Forward. African Journal of Social Sciences and Humanities Research. Vol. 3, Issue 1, pp. 31-43

Abiodun, T.F. (2016). An Appraisal of Nigeria's Counter-Terrorism Policy: The Case of Boko Haram. In Akinwumi, F.S., and Olaniyan, D.A. (Eds.) Global Perspectives in Education. Ibadan: His Lineage Publishing House. 145-155pp. ISBN 978-978-525514-0.

Amitai, E. and Oren, E. (2017).Pros and Cons of Autonomous Weapons Systems. Military Review, The professional Journal of the US Army. Army University Press

Ban, K. (2015) "Insecurities in the Northeast Nigeria: Threat to Global Peace". UN Annual Report on Children and Armed Conflict, UN Secretary-General.

Bartolotta, C. (2011), Terrorism in Nigeria: the Rise of Boko Haram. The Whiteheard Journal of Diplomacy and International Relations.

Chothia, F. (2012), Who are Nigeria's Boko Haram Islamists? BBC News.

Constantine H. H.` and Stuart N. S. (2016). "Linear Control System Analysis and Design”. $M A T L A B$, CRC Press, Sixth Edition.

Enenche, J. (2020). "Two Nigerian soldiers, three Boko Haram fighters killed in an ambushOfficial”. 21 May, 2020 Premium Times.

Friedman, N. (2010). "Unmanned combat air systems. A new kind of carrier aviation”. Naval Institute Press, Annapolis, Maryland, 2010. (ISBN 978-1-59114-285-0).

Gary, E. M. (2017). "International Governance of Autonomous Military Robots," Columbia Science and Technology Law Review 12 (June 2011): 272-76, accessed 27 March 2017, http://stlr.org/download/volumes/volume12/marchant.pdf.

German Press Agency (2020). "Boko Haram kills 92 Chadian, 70 Nigerian soldiers in terror attacks". German Press Agency, 25 March 2020.

Institute for Economics and Peace (2015). "Boko Haram ranked the deadliest terrorist group in 2014”. Institute for Economics and Peace, 2015 Report.

James, R. C. (2007). Unmanned Systems Roadmap: 2007-2032 (Washington, DC: Department of Defense [DOD], 19, accessed 28 March 2020. 
Jason, S. D. (2015). “Automating the Right Stuff? The Hidden Ramifications of Ensuring Autonomous Aerial Weapon Systems Comply with International Humanitarian Law," Air Force Law Review 72 (2015): 85-122, accessed 27 March 2020, http://www.afjag.af.mil/Portals/77/documents/AFD-150721-006.pdf

Jeffrey, S. T. (2012). "Legal Implications of Fully Autonomous Targeting," Joint Force Quarterly 67 (4th Quarter, October 2012): 83, accessed 8 March 2020.

Merrill, B. (2016). "Is the Future of War Autonomous?" http://www.makeuseof.com/tag/future-war-autonomous/ (2016.02.06).

Michael, B. (2014). Nightfall: Machine Autonomy in Air-to-Air Combat. Air and Space Power Journal 23, no. 3 (May-June 2014): 54, accessed 28 April, 2020, http://www.au.af.mil/au/afri/aspj

Miller, N. E. (1941). The Frustration-Aggression Hypothesis. Psychological Review, 48, $337-$ 342.

Nicol, M. (2016). "The Black Hornet - tiny spy drone that can follow enemy targets all the way home" (online) url: http://www.dailymail.co.uk/news/article-2272590

Northrop, G. (2016). "RQ-4 Block 40 Global Hawk". (online) url: http://www.northropgrumman.com/Capabilities/GlobalHawk/Documents

Solon, O. (2016). "The robot army of the future - from killer drones to cyborg super soldiers". Mirror News, United Kingdom.

Szegedi, P. and Bekesi, B. (2015). "Sensors on Board of the Unmanned Aerial Vehicles", Proceedings of 19th International Scientific Conference Transport Means, Kaunas, Lituania, 2015. Pg. 781

The Research Report, 2020.

Warren, S. (2020). "At least 50 Nigerian soldiers killed in Boko Haram ambush" 24 March, 2020. Aljazeera News. 


\section{Other Data Sources}

Air Force, Army

Nigerian Navy

Nigeria Institute for Policy and Strategic Studies, NIPSS, Kuru, Jos, Nigeria

Department of Mechatronic Engineering, Federal University of Technology, Akure, Nigeria

Department of Mechanical Engineering, Yaba College of Technology, Yaba, Lagos, Nigeria

Departments of Mechanical Engineering, Federal University, Oye-Ekiti, Nigeria 